\title{
Experimental Study \\ of Reliability Indicators Injection Feeding System \\ of Gasoline Engines in Road \\ and Climatic Conditions of Central Asia
}

\author{
Bakhrom A. Kayumov* \\ Andijan Machine-building Institute \\ 56 Boburshakh Str., Andijan, Republic of Uzbekistan
}

Received 03.11.2015, received in revised form 27.12.2015, accepted 12.01.2016

The article describes the methodology of conducting tests on measuring the reliability of power supply system injection gasoline engines in road and climate conditions of Central Asia. The results obtained in experiments properly processed and identified characteristics of bounce. Identifies the main factors affecting reliability, i.e. dust environment and due to fuel contamination. Critical power system elements are installed and designed the numeric values of reliability.

Keywords: Reliability, injector, fuel pump, road and climatic conditions, dust, air pollution, fuel supply system, engine.

Citation: Kayumov B.A. Experimental study of reliability indicators injection feeding system of gasoline engines in road and climatic conditions of Central Asia, J. Sib. Fed. Univ. Eng. technol., 2016, 9(1), 86-104. DOI: 10.17516/1999-494X-2016-9-186-104.

\section{Экспериментальные исследования}

\section{показателей безотказности инжекционной}

системы питания бензиновых двигателей

в дорожно-климатических условиях Центральной Азии

\author{
Б.А. Каюмов \\ Андижанский машиностроительный институт \\ Республика Узбекистан, Андижан, Бобуршах, 56
}

В статье изложена разработанная методика проведения испытаний по определению показателей безотказности инжекиионной системы питания бензиновых двигателей в дорожно-климатических условиях Центральной Азии. Полученные результаты при

\footnotetext{
(C) Siberian Federal University. All rights reserved

* Corresponding author E-mail address: bakhrom-kayumov@umail.uz; kayumov_bahrom74@mail.ru
} 
экспериментах должным образом обработаны и определены характерные особенности отказов. Представлены основные факторы, влияющие на безотказность, т.е. запыленность окружающей среды и загрязненность топлива. Установлены критические элементы системь питания и рассчитаны численные значения безотказности.

Ключевые слова: безотказность, инжектор, топливный насос, дорожно-климатические условия, запыленность воздуха, загрязненность топлива, система питания, двигатель.

\section{Введение}

Научное исследование в области прикладных технических наук связано с проведением пассивных или активных экспериментальных наблюдений и установлением научных фактов. В большинстве случаев эти наблюдения необходимо проводить в значительных размерах, чтобы накопить достаточное количество информации. Одно наблюдение, один факт не позволяют делать какие-либо серьезные выводы. Поэтому количество наблюдений и собранных фактов должно быть достаточным, чтобы их осмыслить, понять, спрогнозировать показатели надежности, выявить соответствующие закономерности их распределения и на основе прогноза дать конкретные предложения по улучшению показателей надежности.

Организация наблюдений и экспериментов должна отвечать определенным требованиям, правилам, а полученные результаты - соответствующим образом обработаны [1-4].

\section{Методика проведения эксплуатационных наблюдений для определения показателей безотказности двигателей с инжекционной системой питания}

Методика проведения эксплуатационных наблюдений была разработана с таким расчетом, чтобы, во-первых, получить максимальную и объективную информацию о надежности работы инжекционной системы питания бензиновых двигателей в жарко-климатических условиях и, во-вторых, охватить все регионы Центральной Азии, где эксплуатируются автомобили с инжекционной системой питания, чтобы можно было применить полученные результаты и для климатических зон соседних государств.

Для проведения испытаний прежде всего были выбраны подконтрольные автомобили модели Nexia, поскольку этот вид автомобиля в наибольшем количестве используется как для служебных целей, так и для личного пользования. Немаловажное значение для достоверности полученных результатов наблюдений имеет минимально допустимое количество подконтрольных автомобилей. В соответствии с ГОСТ 17510-72 количество подконтрольных автомобилей в каждой партии должно быть не менее 15. С учетом возможности выбытия автомобилей из испытания по различным причинам количество подконтрольных автомобилей нами было выбрано не менее 25 единиц в каждой группе.

Для всех подконтрольных автомобилей были составлены карты надежности (ГОСТ 27.00283). В эту карту внесены следующие основные исходные данные: год выпуска автомобиля; государственный номер, фамилия, имя, отчество водителя; пробег автомобиля с начала эксплуатации; вид имевшего отказа; причины, вызвавшие отказ; пробег автомобиля в момент появления отказа; дата появления отказа. В момент к началу эксплуатационных наблюдений пробег автомобилей колебался от нескольких до 52 тыс. км. До начала испытаний все автомобили

$$
-87-
$$


подвергались тщательному техническому осмотру, а новые автомобили, включенные в подконтрольную группу, проверялись на наличие в книжках автомобиля регистрации о выполнении предпродажного технического осмотра. При отсутствии такой записи автомобиль подвергался техническому осмотру в программе предпродажного осмотра.

Перед началом эксплуатационных наблюдений для водителей был прочитан краткий курс лекций о сущности и необходимости проведения эксплуатационных наблюдений по определению показателей безотказности инжекционной системы питания двигателей. Часть подконтрольных автомобилей использовали для служебных целей, а основное количество - для личных.

Для определения влияния сезонных климатических условий на надежность систем питания двигателей испытания проводились круглогодично.

Условия эксплуатации климатических зон Центральной Азии включает равнинные, полупустынные и пустынные зоны, а также горные районы, характеризующиеся засушливостью и запыленностью местности, с продолжительным и жарким климатом.

Для того чтобы наиболее полно охватить влияние этих климатических факторов на эксплуатационную надежность инжекционной системы питания автомобильных двигателей, наблюдения проводились в четырех зонах Центральной Азии, отличающихся между собой характерными дорожно-климатическими особенностями окружающей среды. Подконтрольные автомобили во всех четырех регионах эксплуатировались в основном по дорогам с твердыми покрытиями и лишь в отдельных случаях по грунтовым дорогам.

По условиям эксплуатации в зимнее время в первом и во втором регионах примерно $90 \%$ пробега автомобилей можно отнести ко второй и $10 \%$ - к третьей категории условий эксплуатации. По регионам третьей и четвертой групп это соотношение можно принять в следующих значениях: 80 и 20 \% соответственно для второй и третьей категорий условий эксплуатации.

Техническое обслуживание автомобилей во время эксплуатационных наблюдений проходило в строгом соответствии с инструкцией по техническому обслуживанию автомобилей в соответствующих автосервисах и станциях технического обслуживания в местах проведения испытаний.

Практика эксплуатации автомобилей с карбюраторными двигателями показывает, что основное количество отказов топливной аппаратуры вызывается вследствие загрязненности топлива и повышенной запыленности воздуха. Для того чтобы выявить характер и причины появления отказов в системах питания двигателей с инжекционной системой питания, мною было уделено особое внимание на разработку методики по определению численных значений показателей эксплуатационной надежности системы питания подконтрольных автомобилей. Правильность такого подхода подтверждается тем, что эксплуатация автомобилей в условиях Центрально-Азиатского региона приводит к частым случаям преждевременного выхода из строя двигателей и их систем питания. Кроме того, основной целью эксплуатационных наблюдений служит выявление причин преждевременного выхода из строя элементов инжекционной системы питания двигателей в условиях жаркого климата и высокой запыленности окружающей среды. Наряду с этим ставилась задача определения обоснованных сроков проведения технического обслуживания инжекционной системы питания двигателей. 
Каждый случай появления отказа в инжекционной системе фиксировался в карте надежности двигателей. При этом производилась запись о дате появления отказа, возможная причина и характер появления отказа, наименование детали или узла, имевшего место в отказе. Карта надежности заполнялась эксплуатационными данными об отказах элементов инжекционной системы питания специально закрепленным для этой цели специалистом, назначенным из числа инженерно-технических работников предприятия. Каждая заполненная карта надежности подконтрольных автомобилей систематически контролировалась ответственным лицом проведения эксплуатационных наблюдений и в конце испытаний утверждалась руководителями предприятий.

Перед проведением наблюдений проверяли работоспособность и техническое состояние у каждой системы питания двигателей и в случае обнаружения несоответствия каких-либо характеристик требованиям технических условий техническое состояние системы приводили в норму.

В период проведения эксплуатационных наблюдений в подконтрольных автомобилях использовался бензин марки не ниже А-76. Периодически отбирали пробы из заправленного в автомобиль топлива для оценки степени загрязненности бензина различными примесями. Пробы отбирались по 250 мл из каждого бензобака до и после топливного фильтра в специально подготовленные для этой цели пробирки. Отобранные пробы подвергались анализу с целью определения количества загрязняющих топливо механических частиц примесей, оценки степени загрязненности бензина и дисперсного состава механических абразивных частиц загрязнений. Анализ отобранных проб производился в соответствии с ГОСТ 2084-77 на содержание механических примесей, загрязнений и воды в топливе. Дисперсный или количественный состав абразивных частиц загрязнений проверялся методом подсчета количества частиц по их размерным группам при помощи биологического микроскопа типа МБИ-3. Размерная группа частиц имела следующую разбивку: $2 \ldots 4$ мкм, $4 \ldots 6$ мкм, $6 \ldots 8$ мкм, $8 \ldots 10$ мкм и т.д.

Параллельно исследовалась и дорожная пыль с поверхностей капота, кабины и отложения из топливных фильтров подконтрольных автомобилей, эксплуатирующихся в различных районах мест испытаний.

При определении дисперсного состава загрязнителей для приготовления проб брали навески дорожной пыли и отложений из фильтров массой 10 мг и распределяли ее в 100 мл бензина. Из продиспергированной пробы отбирали 1 мл суспензии, разбавляли в 14 мл бензина и фильтровали через мембранный фильтр. Фильтр с осевшими частицами загрязнений подсушивали, просветляли раствором с равными пропорциями гексана и дихлорэтана, после чего просматривали под микроскопом.

При оценке показателей безотказности инжекционной системы питания двигателей фиксировались как общие отказы системы питания, так и отказы из-за загрязнений бензина. Отказы, вызванные загрязнениями топлива, выявлялись во время устранения общих отказов системы питания. К отказам элементов системы питания по причине загрязненности бензина относятся засорение или износ каналов инжектора, забивание фильтров топливного насоса и инжектора загрязнениями топлива, забивание отверстия впрыска инжектора смолистыми загрязнениями топлива и т. п. 
Сбор информации о показателях эксплуатационной надежности двигателей с инжекционной системой питания производился систематически, далее показатели подвергались обработке при помощи вероятностно-статистических методов и программного метода сплайнфункций. Обработанные данные анализировали.

\section{Исследования влияний загрязненности топлива \\ и запыленности воздуха окружающей среды}

\section{на эксплуатационную надежность инжекционных систем питания двигателей}

Результаты исследования загрязненности топлива показали, что в бензине содержится значительное количество загрязняющих примесей органического и неорганического происхождения. Количественный и размерный анализ загрязняющих примесей продемонстрировал, что количество содержащихся в бензине загрязняющих примесей зависит от уровня запыленности окружающей среды места проведения испытаний и колеблется от 90 до 300-500 г/т топлива, а размеры частиц загрязнений находятся в интервале 3-50 мкм, причем основное количество размеров загрязнений составляют частицы с размерами 3-10 мкм. Полученные при помощи статистических обработок данные по определению уровня загрязненности бензинов в баках подконтрольных автомобилей показывают (табл. 1.), что количество загрязняющих примесей в топливных баках автомобилей находится в прямой зависимости от запыленности окружающей среды мест эксплуатации, а с повышением уровня запыленности воздуха количество загрязняющих механических примесей в топливе увеличивается. Следует отметить, что в табл. 1 представлены осредненные значения данных по загрязненности бензина в баках подконтрольных автомобилей. Однако в отдельных случаях количество загрязняющих примесей при разовых извлечениях из баков подконтрольных автомобилей, эксплуатирующихся в регионах Туранской низменности, доходило до 2,3 г в 1 л слитого бензина.

Отметим, что по внешнему виду основные загрязняющие примеси состояли из частиц дорожной пыли в виде мелких песчинок. Это свидетельствует о том, что основным загрязнителем бензина является дорожная пыль. Это подтверждается также и данными, представленными в табл. 1. из которых видно, что с повышением запыленности окружающего воздуха количество механических частиц загрязнений в топливе увеличивается. Следовательно, между запыленностью окружающей среды и загрязненностью бензина имеется определенная корреляционная зависимость.

Таблица 1. Средние значения запыленности воздуха и количества загрязняющих примесей бензина в баках подконтрольных автомобилей

\begin{tabular}{|c|c|c|}
\hline Место проведения наблюдений & Запыленность воздуха, г/м³ & Загрязненность бензина, г/т \\
\hline I регион & $0,16-0,21$ & 105,3 \\
\hline II регион & $0,25-0,32$ & 153,4 \\
\hline III регион & $0,62-0,75$ & 276,0 \\
\hline IV регион & $0,51-0,6$ & 197,0 \\
\hline
\end{tabular}


Таблица 2. Среднемесячные технико-эксплуатационные и климатические показатели работы автомобилей

\begin{tabular}{|c|c|c|c|}
\hline \multirow[t]{2}{*}{ Показатель } & \multicolumn{2}{|c|}{$\begin{array}{c}\text { Период } \\
\text { эксплуатации }\end{array}$} & \multirow{2}{*}{$\begin{array}{c}\text { Отношение летних } \\
\text { показателей к зимним }\end{array}$} \\
\hline & лето & зима & \\
\hline Пробег автомобиля в месяц, тыс. км & 7,41 & 7,0 & 1,06 \\
\hline Среднетехническая скорость движения, км/ч & 34,2 & 33,1 & 1,0 \\
\hline Абсолютная максимальная температура воздуха, ${ }^{0} \mathrm{C}$ & 43,4 & 7,4 & 5,9 \\
\hline Среднегодовая температура окружающей среды, ${ }^{0} \mathrm{C}$ & 16,1 & $-2,7$ & 7,0 \\
\hline Уровень запыленности атмосферного воздуха, г/м³ & 0,37 & 0,15 & 2,5 \\
\hline
\end{tabular}

Однако вода все же поступает в состав топлива подконтрольных автомобилей. Это, по-видимому, происходит в результате конденсации ее паров из воздуха на внутренних стенках емкостей, в которых хранится топливо, и топливных баков автомобилей при больших колебаниях перепадов температуры окружающей среды и внутренних стенок емкостей.

Среднемесячные эксплуатационные показатели и климатические условия работы подконтрольных автомобилей за период наблюдений приведены в табл. 2.

Из представленных в табл. 2 результатов следует, что автомобили в летнее время эксплуатировались несколько интенсивнее, чем зимой. Абсолютно-максимальная температура воздуха даже и в зимнее время имеет плюсовое значение, а запыленность воздуха - достаточно высокий уровень и составляет 0,15 г/м ${ }^{3}$. Уровень запыленности окружающей среды в местах наблюдений в летнее время в 2,5 раза больше, чем зимой. Следовательно, степень загрязненности топлива в баках автомобилей в летнее время может быть значительно выше по сравнению с зимним периодом. За зимний период условно были приняты ноябрь, декабрь, январь, февраль, а остальные месяцы отнесены к летним.

\section{Определение численных значений показателей безотказности элементов системы питания подконтрольных автомобилей}

Для наглядности оценки и удобства сравнения данных результаты эксплуатационных наблюдений подконтрольных автомобилей представлены раздельно для каждого региона испытаний инжекционных систем питания. Данные о пробеге автомобилей за период наблюдений приведены в табл. 3.

Данные табл. 3 свидетельствуют о том, что приведенные к среднегодовому значению пробеги автомобилей за время испытаний по регионам мест наблюдений имеют небольшой разброс и находятся в пределах 85,4...106,2 тыс. км, причем более половины пробегов подконтрольных автомобилей приходится на сухую пыльную погоду. Для определения показателей безотказности инжекционной системы питания двигателей, как уже отмечалось, фиксировались все отказы, возникшие в ней за период эксплуатационных наблюдений подконтрольных автомобилей. И при этом обработка и анализ характера причин возникновения и последствий отказов системы питания двигателей осуществлялись в соответствии со схемой, представленной на рис. 1. 
Таблица 3. Среднегодовые пробеги подконтрольных автомобилей за время эксплуатационных наблюдений

\begin{tabular}{|c|c|c|c|c|}
\hline \multirow{2}{*}{$\begin{array}{c}\text { Место проведения } \\
\text { наблюдений }\end{array}$} & \multicolumn{2}{|c|}{ Пробеги автомобилей в период испытаний, тыс. км } \\
\cline { 2 - 5 } & среднегодовой & \multicolumn{2}{c|}{ при сухой погоде } \\
\cline { 2 - 5 } & топливный насос & инжектор & топливный насос & инжектор \\
\hline I регион & 88,257 & 86,395 & 61,495 & 60,100 \\
\hline II регион & 98,877 & 89,998 & 69,683 & 62,999 \\
\hline III регион & 95,126 & 106,15 & 66,588 & 74,312 \\
\hline IV регион & 101,878 & 92,375 & 71,408 & 64,681 \\
\hline По всем регионам & 95,035 & 93,729 & 67,294 & 65,524 \\
\hline
\end{tabular}

\begin{tabular}{l}
\hline $\begin{array}{c}\text { Схема анализа характера, причин возникновения и } \\
\text { последствий отказов }\end{array}$ \\
\begin{tabular}{|c|}
\hline Составление перечня всех элементов системы питания двигателя \\
\hline Составление перечня учитываемых видов отказов, описание и идентификация \\
рассматриваемого элемента системы
\end{tabular} \\
\hline Разработка задания интенсивности отказов для каждого типа отказа элемента \\
\hline Составление перечня воздействий отказов каждого типа на элементы и систему \\
питания в целом \\
\hline
\end{tabular}

Составление замечаний по каждому рассматриваемому типу отказов элементов

Анализ критических отказов каждого типа, отказов, лимитирующих надежность работы системы топливоподачи

Разработка необходимых мероприятий по предупреждению возникновения каждого типа отказов

Рис. 1. Схема анализа характера, причин возникновения и последствий отказов системы топливоподачи двигателя

Такой анализ позволяет установить степень влияния отказов на безотказность системы питания двигателя, составить перечень возможных отказов для каждой детали и выявить степень их влияния на данный узел или деталь системы, установить причины, вызвавшие отказ данного элемента, разработать путь к предупреждению их нового появления и др. В результате эксплуатационных наблюдений получено, что в инжекционной системе питания двигателей имело место следующее количество отказов (табл. 4).

Полученные данные показывает, что суммарный среднегодовой пробег подконтрольных автомобилей за период наблюдений по регионам колебался в интервале 4714,2 ...21345,7 тыс. км,

$$
-92-
$$


Таблица 4. Количество отказов элементов инжекционной системы питания двигателей подконтрольных автомобилей за период эксплуатационных наблюдений

\begin{tabular}{|c|c|c|c|c|c|c|}
\hline \multirow{2}{*}{ Показатели } & \multicolumn{4}{|c|}{ Регионы мест наблюдений } & \multicolumn{2}{|c|}{$\begin{array}{c}\text { По всем } \\
\text { регионам }\end{array}$} \\
\hline & I & II & III & IV & общее & среднее \\
\hline Количество подконтрольных автомобилей & 27 & 113 & 72 & 32 & 244 & 61 \\
\hline $\begin{array}{l}\text { Суммарный среднегодовой пробег автомобиля } \\
\text { в период наблюдений, тыс. км }\end{array}$ & 4714,2 & 21345,7 & 14490,2 & 6217,6 & 46767,7 & 11691,9 \\
\hline $\begin{array}{l}\text { Количество отказов на систему питания, } \\
\text { всего, }\end{array}$ & 142 & 668 & 518 & 225 & 1563 & 391 \\
\hline в том числе: & & & & & & \\
\hline инжектор & 50 & 254 & 173 & 79 & 556 & 139 \\
\hline электрический топливный насос & 58 & 309 & 209 & 90 & 676 & 169 \\
\hline электронный блок управления с датчиками & 8 & 18 & 18 & 10 & 54 & 14 \\
\hline топливный фильтр & 12 & 38 & 52 & 24 & 126 & 32 \\
\hline другие узлы и детали & 14 & 49 & 66 & 22 & 151 & 38 \\
\hline $\begin{array}{l}\text { Средняя наработка на отказ системы питания, } \\
\text { тыс. км }\end{array}$ & 33,2 & 31,95 & 27,97 & 28,25 & 118,12 & 29,53 \\
\hline
\end{tabular}

а по всем регионам в среднем 11691,9 тыс. км, что свидетельствует о высокой интенсивности эксплуатации автомобилей в регионах наблюдений.

Среднее количество отказов по инжекционной системе питания двигателей, приходящееся на один автомобиль, составило 6,4 единицы при пробеге 191,7 тыс. км. Среднее наработка отказов по инжекционной системе питания в зависимости от региона наблюдений колебалась в интервале 27,97...33,20 тыс. км, а в среднем по всем регионам 29,53 тыс. км. Из этого следует, что средняя наработка на отказ имеет небольшой разброс, вызванный как случайностью процессов появления отказов, так и отличием отдельных эксплутационных факторов мест наблюдений.

Для более подробной оценки и анализа показателей безотказности количество отказов рассматривалось в распределенном виде по элементам системы питания двигателей (табл. 5).

Распределение общего количества отказов по элементам системы питания двигателей показывает, что основное количество отказов приходится на инжектор и электрический бензонасос, величина которого в зависимости от региона эксплуатации находится: для инжектора $50 \ldots 254$ отказа и топливного насоса $-58 . .309$ отказов за весь период эксплуатации. Среднее количество отказов по региону приходится на инжектор - 139, на топливный насос - 169. Это показывает, что топливные насосы по отношению к инжектору имели в 1,2 раза большее количество отказов. Такая тенденция наблюдалась по всем регионам мест наблюдений, и это является свидетельством того, что конструкция топливных насосов менее надежна, чем инжектора.

Значительное количество отказов приходится на топливные фильтры, и в зависимости от региона эксплуатации оно колеблется от 10 до 53. Характерным отказом топливных фильтров стало преждевременное частичное или полное забивание фильтрующих элементов загрязняющими примесями и смолистыми веществами топлива, приводящими к повы- 
Таблица 5. Распределение количества отказов по элементам системы питания подконтрольных автомобилей

\begin{tabular}{|c|c|c|c|c|c|}
\hline \multirow{2}{*}{ Показатели безотказности } & \multicolumn{4}{|c|}{ Регионы мест наблюдений } & \multirow{2}{*}{$\begin{array}{c}\text { Среднее по } \\
\text { регионам }\end{array}$} \\
\hline & I & II & III & IV & \\
\hline $\begin{array}{l}\text { Средний годовой пробег, приходящийся на один } \\
\text { автомобиль, тыс. км }\end{array}$ & 174,6 & 188,9 & 201,2 & 194,3 & 189,7 \\
\hline $\begin{array}{l}\text { Количество отказов по системе питания, всего: } \\
\text { в том числе: }\end{array}$ & 142 & 668 & 518 & 225 & 391 \\
\hline инжектор & 50 & 254 & 173 & 79 & 139 \\
\hline электрический бензонасос & 58 & 309 & 209 & 90 & 169 \\
\hline электронный блок управления с датчиками & 9 & 17 & 30 & 14 & 17,5 \\
\hline топливный фильтр & 10 & 42 & 53 & 23 & 32,2 \\
\hline другие узлы и детали & 15 & 46 & 53 & 19 & 33,3 \\
\hline $\begin{array}{l}\text { Количество отказов из-за загрязнений бензина } \\
\text { всего: }\end{array}$ & 58,2 & 265,2 & 231,2 & 96,7 & 162,8 \\
\hline в том числе: & & & & & \\
\hline инжектор & 17,4 & 84,8 & 76,2 & 36,7 & 53,8 \\
\hline электрический бензонасос & 19,1 & 90,1 & 85,9 & 43,5 & 59,6 \\
\hline электронный блок управления с датчиками. & 2,1 & 7,1 & 10,1 & 47 & 6 \\
\hline топливный фильтр & 6,5 & 25 & 30,8 & 13 & 18,8 \\
\hline другие узлы и детали & 2,5 & 11 & 14 & 8 & 8,9 \\
\hline $\begin{array}{l}\text { Интенсивность общих отказов по системе } \\
\text { питания, отказ/1000 км }\end{array}$ & 0,003 & 0,031 & 0,036 & 0,036 & 0,033 \\
\hline
\end{tabular}

шению гидравлического сопротивления фильтра и в конечном счете прекращению подачи топлива.

Для более детального анализа и оценки показателей надежности были рассмотрены характер и количество отказов с распределением их по элементам инжекционной системы питания двигателя, приведенные к одному автомобилю (табл. 6).

Количество отказов элементов электронного блока управления (ЭБУ) находится в интервале $0,15 \ldots 0,44$, а число отказов, происходивших из-за загрязнений бензина, в среднем для всех регионов составило 0,1 . Отказами ЭБУ считались такие отказы и неисправности, когда его элементы, работавшие с топливом, имели существенные помехи или же переставали давать показания о состоянии контролируемого ими объекта.

Элементами, имевшими наибольшее число отказов, являлись инжектор и электрический бензонасос, средняя величина которых 2,28 и 2,77, а число отказов из-за загрязнений бензина 0,88 и 1,01 соответственно.

Анализируя характер и причины возникновения отказов, можно прийти к выводу, что более чем $40 \%$ отказов в элементах инжекционной системы питания вызываются загрязнениями топлива и главным образом механическими твердыми частицами пыли.

Результаты эксплуатационных наблюдений подконтрольных автомобилей позволили установить следующие основные причины появления и виды отказов топливной аппаратуры двигателей:

в инжекторе: 
Таблица 6. Распределение количества отказов по элементам инжекционной системы питания двигателя одного автомобиля

\begin{tabular}{|c|c|c|c|c|c|}
\hline \multirow{2}{*}{ Показатели безотказности } & \multicolumn{4}{|c|}{ Регионы мест наблюдений } & \multirow{2}{*}{$\begin{array}{c}\text { Среднее } \\
\text { по регионам }\end{array}$} \\
\hline & I & II & III & IV & \\
\hline Пробег одного автомобиля, тыс. км & 174,6 & 188,9 & 201,2 & 194,3 & 189,7 \\
\hline $\begin{array}{l}\text { Количество отказов по системе питания, всего: } \\
\text { в том числе: }\end{array}$ & 5,3 & 5,9 & 7,2 & 7,03 & 6,4 \\
\hline инжектор & 1,85 & 2,24 & 2,45 & 2,46 & 2,28 \\
\hline электрический бензонасос & 2,15 & 2,73 & 2,9 & 2,81 & 2,77 \\
\hline электронный блок управления с датчиками & 0,33 & 0,15 & 0,42 & 0,44 & 0,29 \\
\hline топливный фильтр & 0,37 & 0,37 & 0,74 & 0,72 & 0,53 \\
\hline другие узлы и детали & 0,55 & 0,41 & 0,74 & 0,59 & 0,55 \\
\hline $\begin{array}{l}\text { Количество отказов из-за загрязнений бензина, } \\
\text { всего: }\end{array}$ & 2,16 & 2,35 & 3,21 & 3,02 & 2,65 \\
\hline $\begin{array}{l}\text { в том числе: } \\
\text { инжектор }\end{array}$ & 0,64 & 0,74 & 1,06 & 1,15 & 0,88 \\
\hline электрический бензонасос & 0,7 & 0,80 & 1,19 & 1,36 & 1,01 \\
\hline электронный блок управления с датчиками & 0,08 & 0,06 & 0,14 & 0,15 & 0,1 \\
\hline топливный фильтр & 0,24 & 0,22 & 0,43 & 0,41 & 0,31 \\
\hline другие узлы и детали & 0,09 & 0,08 & 0,19 & 0,25 & 0,15 \\
\hline $\begin{array}{l}\text { Интенсивность общих отказов по системе } \\
\text { питания, отказ/1000 км: общих }\end{array}$ & 0,03 & 0,031 & 0,036 & 0,036 & 0,033 \\
\hline из-за загрязнений бензина & 0,012 & 0,012 & 0,016 & 0,015 & 0,014 \\
\hline
\end{tabular}

- забивание фильтра и отверстий инжекторов смолистыми отложениями топлива;

- заклинение клапана инжектора в результате прилипания смолистых липких отложений к внутренним стенкам инжектора и попадания в зазоры механических частиц загрязнений;

- изнашивание впрыскного канала инжектора под абразивными действиями механических частиц загрязнений топлива;

в электрическом топливном насосе:

- забивание фильтра топливного насоса твердыми механическими примесями и органическими смолистыми загрязнениями топлива;

- затормаживание появления электрического поля из-за прилипания механических и минеральных примесей топлива к статору электропривода насоса;

- износ щеток и якоря электропривода топливного насоса из-за абразивных действий механических частиц загрязнений топлива.

В каждой технической системе имеется определенное количество элементов, надежностью работы которых определяется надежность всей системы, т.е. такие элементы являются «критическими» элементами или деталями, лимитирующими надежность, в данном случае это инжекционная система питания двигателя.

Детальный анализ материалов эксплуатационных наблюдений позволил определить, что надежность работы инжекционной системы питания бензиновых двигателей автомобилей Neхіа 
определяется прежде всего безотказностью инжектора и электрического топливного насоса. Следовательно, сроки службы данных элементов меньше, чем у двигателя, и расходами на поддержание технического состояния или замены этих элементов определяются и эксплуатационные затраты на поддержание инжекционной системы питания в технически исправном состоянии.

В связи с этим представляет определенный интерес знание закономерностей распределения показателей безотказности инжектора и топливных насосов, и поэтому автором были обработаны материалы эксплуатационных наблюдений для оценки показателей их безотказности с применением вероятностно-статистического метода. Расчеты производились раздельно для каждого региона мест эксплуатационных наблюдений, на основании которых были построены кривые закономерностей распределения наработок на отказ для инжектора и топливного насоса по регионам мест эксплуатационных наблюдений (рис. 2 и 3). Судя по характеру кривых, можно отметить, что плотность распределения отказов инжекторов и топливных насосов, несмотря на значительные различия в климатических условиях эксплуатации подконтрольных автомобилей, имеют одинаковую закономерность появления отказов.

Хорошая сходимость кривых, полученных по эксплуатационным данным с расчетными, создает уверенность в правильности найденных закономерностей.

Таким образом, на основании результатов обработки материалов обширных эксплуатационных наблюдений с применением вероятностно-статистического метода можно сказать, что отказы элементов инжекционной системы питания двигателей имеют случайный характер и вероятность их появления при условии эксплуатации автомобилей Nexia в регионах Центральной Азии подчиняется нормальному закону распределения плотности случайных величин.

Подчеркнем, что при рассмотрении причин, вызвавших отказы элементов системы, наблюдались случаи образования на поверхностях деталей трудноудаляемых отложений темного цвета, образовавшихся в результате смешивания механических примесей со смолистыми загрязнениями топлива под воздействием высокой температуры подкапотного пространства.

Для предупреждения появления таких отказов элементов системы питания двигателей на всех автомобилях установлены топливные фильтры для очистки топлива от механических частиц загрязнений и воды. Согласно данным завода-изготовителя, фильтр предварительной очистки, устанавливаемый обычно в топливном баке, имеет тонкость отсева 50 мкм, а фильтр тонкой очистки - 5-10 мкм. Это свидетельствует о том, что все твердые частицы загрязнений топлива с размером менее 5-10 мкм могут проходить через фильтры и свободно попадают к элементам системы питания, а затем в цилиндры двигателя. Если учесть, что основное количества механических частиц загрязнений топлива имеют размеры меньше чем 8-10 мкм, можно сделать вывод, что в образовании смолистых отложений на деталях участвует большое число частиц механических загрязнений топлива.

Результаты анализа характера и причин появления отказов, а также уровня загрязненности топлива в баках подконтрольных автомобилей показывают, что система очистки топлива двигателей автомобилей имеет недостаточную эффективность работы и не обеспечивает требуемое качество очистки топлива и защиту двигателей от попадания в них механических частиц загрязнений. И это является одной из главных причин, приводящих к частым отказам элементов инжекционной системы питания двигателей. 

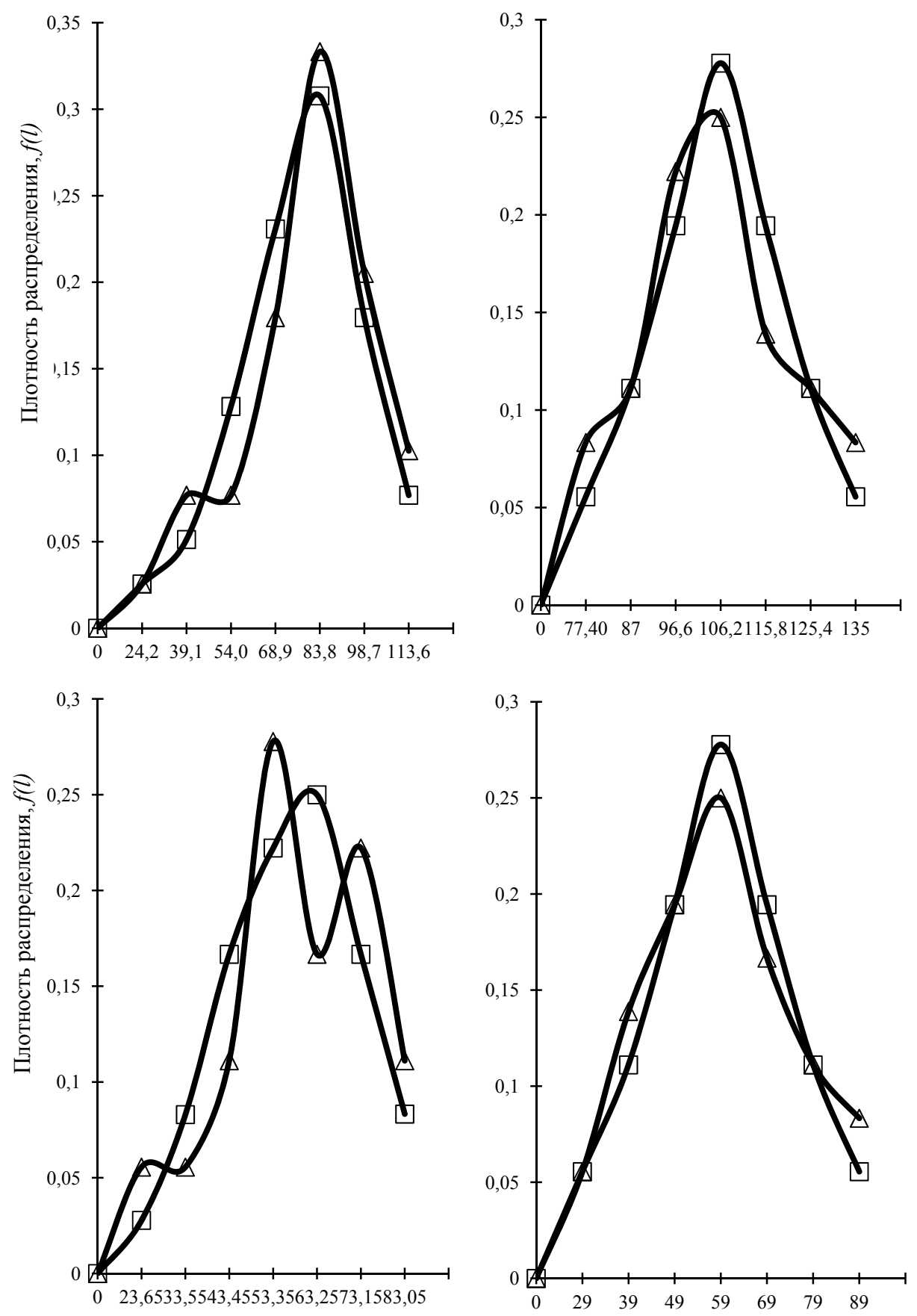

Наработка на отказ, (l) тыс. км

Рис. 2. Закономерности плотности (m) распределений средней наработки на отказ $(l)$ инжектора системы питания по регионам: а - регион-1; б - регион-2; в регион-3; д - регион-4; 1 - эксплуатационная; 2 - расчетная 

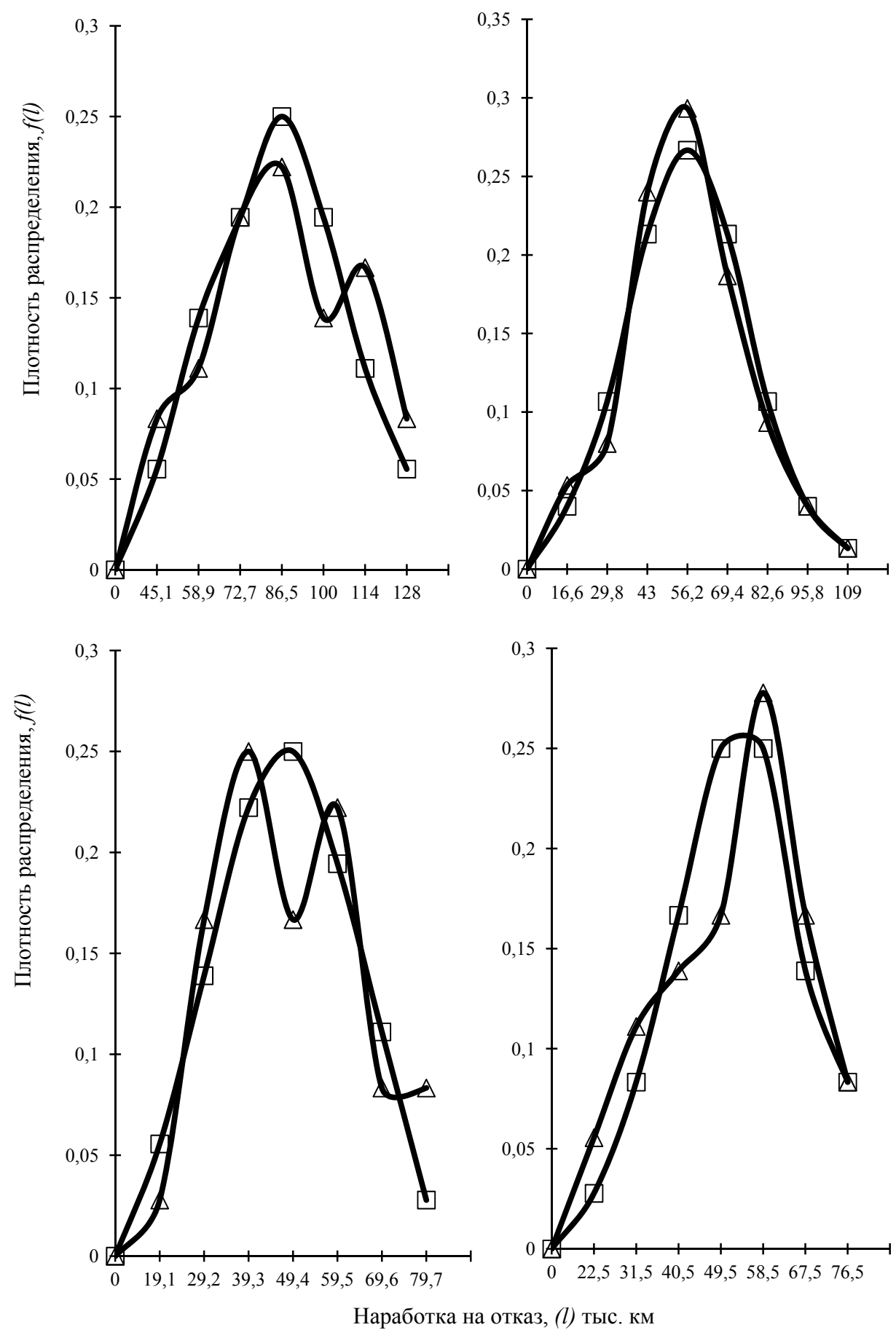

Рис. 3. Закономерности плотности $(\mathrm{m})$ распределений средней наработки на отказ $(l)$ топливного насоса системы питания по регионам: а-регион-1; б - регион-2; в - регион-3; д - регион-4. 1 - эксплуатационная; 2 - расчетная 
Подтверждением этому является то, что загрязняющие примеси в бензине, попадая в инжекционную систему, вызывают засорение каналов и седла клапанов инжектора, а абразивные частицы, вызывая изнашивание отверстий впрыска топлива инжектора, щеток якоря электродвигателя топливного насоса, приводят к нарушению нормы при подаче топлива.

Топливный насос перекачивает бензин при помощи электродвигателя, установленного внутри него, и топливо проходит через электродвигатель. При работе на чистом бензине электродвигатель работает нормально, поскольку электропроводимость бензина равна нулю. В случае наличия воды в бензине она, проходя через каналы между статором и ротором электродвигателя, производит короткое замыкание, что приводит к перегоранию обмоток электродвигателя и отказу топливного насоса.

При работе подконтрольных автомобилей на топливе с повышенным содержанием смол наблюдались случаи интенсивного загрязнения инжекционной системы питания. Выпавшие при испарении основной части бензина смолы отлагаются на стенках топливного трубопровода, внутренних каналах инжектора и под действием температуры превращаются в твердые трудноудаляемые отложения. При этом по мере удаления от топливного бака отложения становятся более твердыми, в них уменьшается количество асфальтенов и увеличивается количество карбенов и карбоидов.

Слой смолистых отложений вызывает дополнительное сопротивление в трубопроводах, в инжекторах и снижает качество рабочей смеси. Отложения на клапанах и седлах клапанов нарушают нормальную работу инжектора и могут привести к забиванию впрыскных отверстий инжектора.

Таким образом, результаты эксплуатационных испытаний подтвердили ранее принятую мною гипотезу о вредном влиянии загрязненности топлива и запыленности воздуха на показатели надежности работы элементов системы питания автомобилей, работающих в условиях эксплуатации Центральной Азии. Загрязненность топлива в баках подконтрольных автомобилей приводит к загрязнению, а затем к постепенному появлению отказов элементов системы питания. Поэтому одним из наиболее доступных и экономически выгодных направлений работ по увеличению безотказности инжекционных систем питания двигателей является обеспечение в них эффективной очистки воздуха, топлива и масла, уплотнение всех мест возможного проникновения пыли в двигатель, а также применение качественного топлива и своевременное техническое обслуживание инжекционной системы питания.

\section{Комплексный анализ результатов исследования и разработка научно-технических рекомендаций по повышению эксплуатационной надежности инжекционной системы питания бензиновых двигателей}

Полученные в результате эксплуатационных испытаний численные значения показателей безотказности элементов инжекционной системы питания двигателей позволили определить оптимальную периодичность выполнения работ по их техническому обслуживанию и ремонту.

Для снижения трудоемкости и обеспечения вычислительных работ, а также повышения достоверности полученных результатов для расчетов по определению периодичности выпол- 
нения технического обслуживания инжекционной системы питания подконтрольных двигателей был использован программный сплайн-метод.

Особенностью современного этапа развития экспериментальных исследований является их автоматизация на основе широкого внедрения средств вычислительной техники. Автоматизация экспериментальных исследований, разработка и внедрение новых методов обработки данных позволяют расширить возможности экспериментальных установок, организовать новые направления исследований, повысить производительность труда исследователей и эффективность использования дорогостоящего оборудования.

Важным направлением экспериментальных исследований являются стендовые испытания новых материалов и сложных объектов на воздействие климатических, механических, акустических и других факторов окружающей среды, проводимые в автомобилестроении, авиа- и ракетостроении, электронной технике, материаловедении, приборостроении, при изучении надежности машин и механизмов и в ряде других отраслей промышленности. Основная цель стендовых испытаний - повышение качества, надёжности и долговечности изделий новой техники при уменьшении их материалоёмкости и стоимости путём воспроизведения состояний, соответствующих состояниям, наблюдаемым в реальных эксплуатационных условиях.

В практике научных исследований часто сталкиваются с задачей, в которой по экспериментальным данным необходимо восстановить общий характер явления или процесса.

Классическим решением данной задачи служит выбор из допустимого множества функций такой, которая наилучшим образом приближается к совокупности экспериментальных данных. Чаще всего для оценки меры качества приближения функции к экспериментальным данным используется величина среднеквадратичной ошибки. В этом случае практической реализацией данного подхода является метод наименьших квадратов.

Но применение метода наименьших квадратов приводит к решению систем алгебраических уравнений. Для систем, функционирующих в реальном масштабе времени, в том числе для многих стендовых испытаний, необходима разработка новых эффективных методов, не требующих решения систем уравнений. Одним из путей решения этой проблемы выступает применение сплайн-методов приближения экспериментальных данных $[5,6]$.

Широкая популярность сплайн-методов объясняется тем, что они служат универсальным инструментом приближения функций и по сравнению с другими математическими методами при равных с ними информационных и аппаратных затратах обеспечивают большую точность.

Сплайн-метод исследования отказов инжекционных систем питания бензиновых двигателей основан на применения сплайнов [6]. Сплайны являются универсальным инструментом обработки экспериментальных данных и по сравнению с другими математическими методами дают большую точность вычислений. Программные модули разработаны на алгоритмическом языке высокого уровня $\mathrm{C}++$.

Для определения численных значений оптимальной периодичности выполнения технического обслуживания элементов, лимитирующих надежность инжекционной системы питания бензиновых двигателей, был применен программный метод сплайн-функций. С помощью моделирования методом сплайн-функций были построены кривые закономерностей распределения наработок на отказ для инжектора и топливного насоса по регионам мест эксплуатаци- 

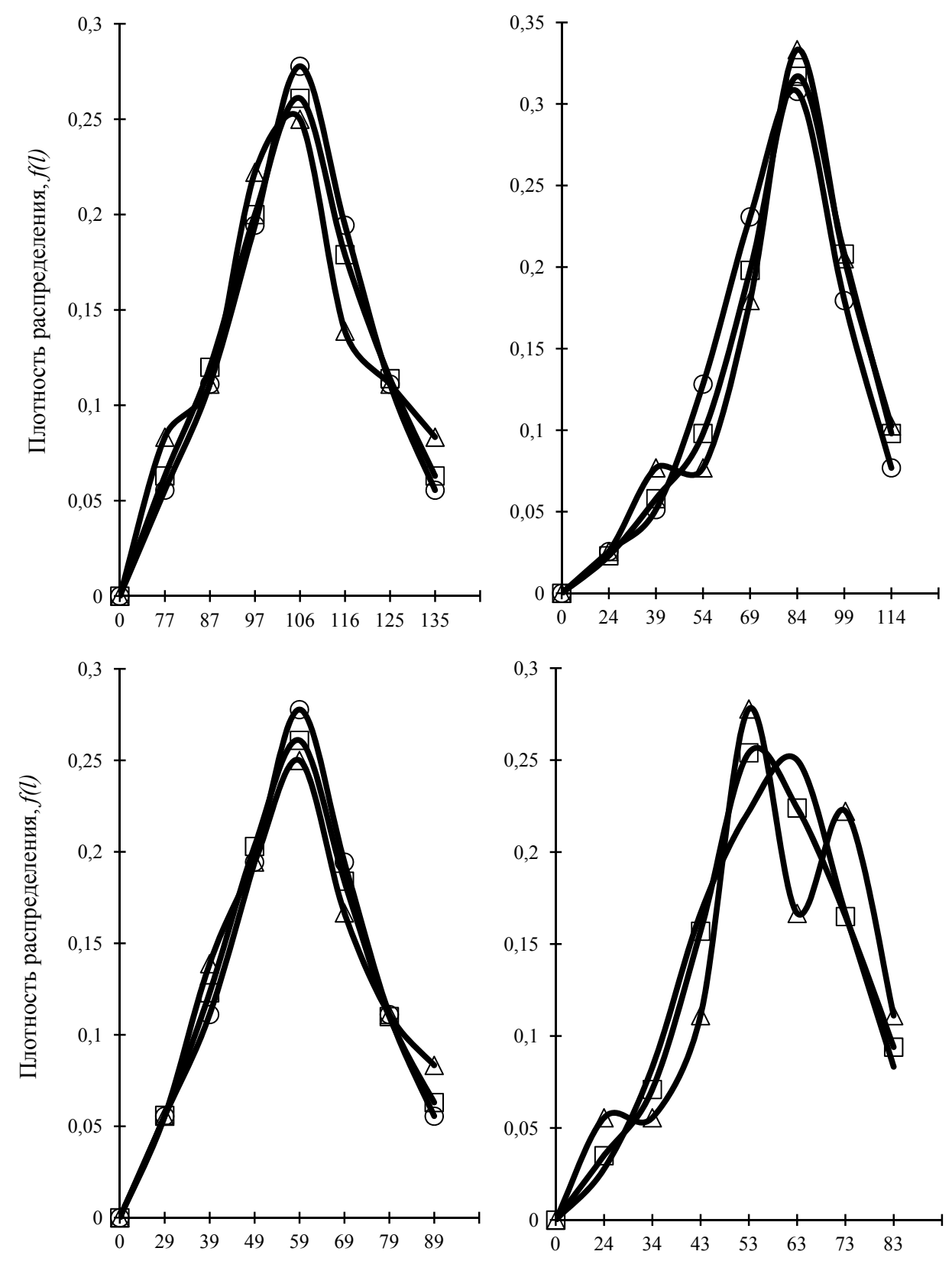

Наработка на отказ, (l) тыс. км

Рис. 4. Определение оптимальной периодичности выполнения ТО и ремонта инжектора системы питания с применением программного сплайн-метода по регионам: а - регион-1; б - регион-2; в - регион-3; д - регион-4. 1 - эксплуатационная; 2 - расчетная; 3 - сплайн-функция 

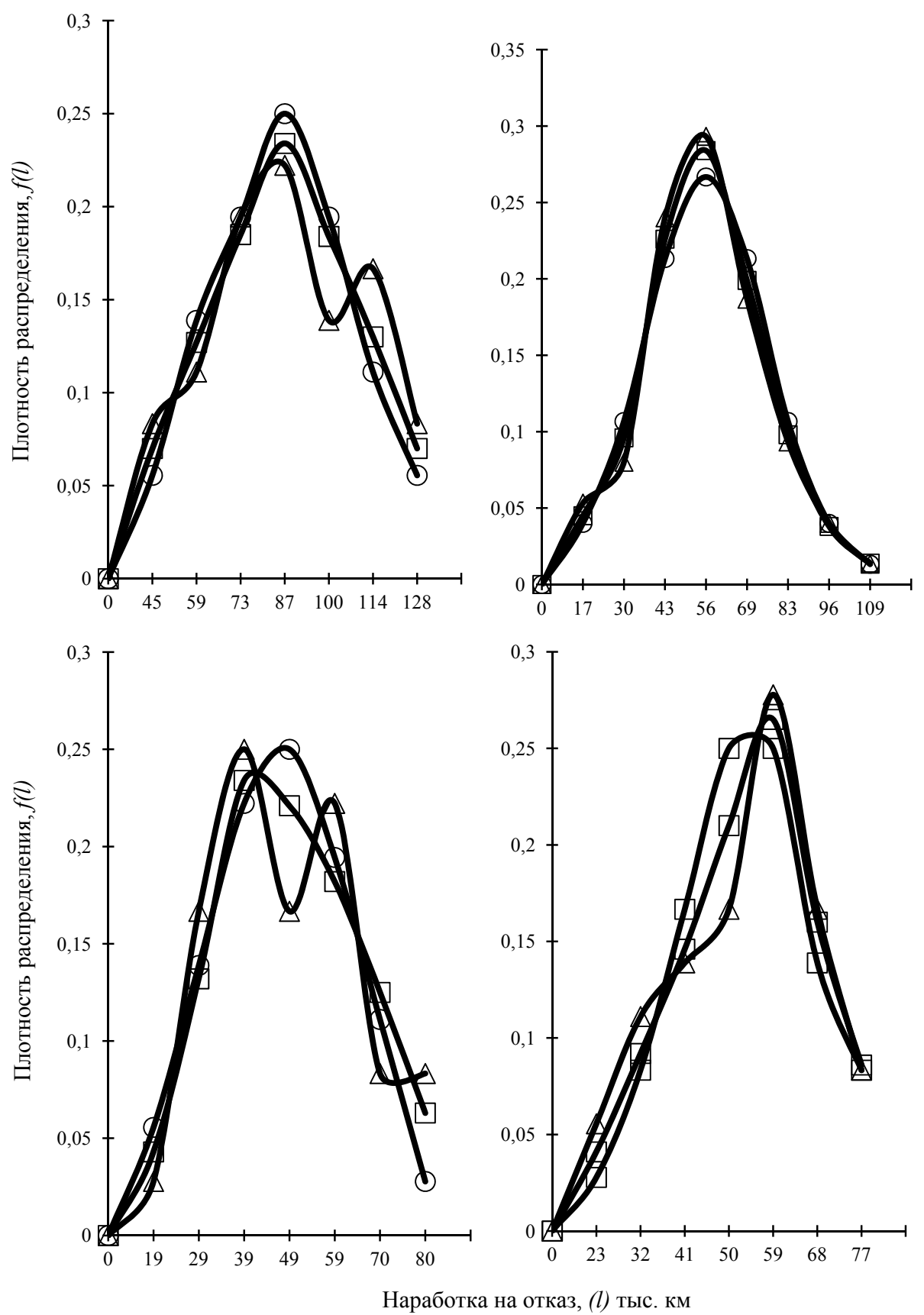

Рис. 5. Определение оптимальной периодичности выполнения ТО и ремонта топливного насоса системы питания с применением программного сплайн-метода по регионам: a - регион-1; б - регион-2; в - регион-3; д - регион-4. 1 - эксплуатационная; 2 - расчетная; 3 - сплайн-функция 
Таблица 7. Оптимальные значения для проведения технического обслуживания элементов инжекционной системы питания

\begin{tabular}{|c|c|c|}
\hline \multirow{2}{*}{ Регионы мест наблюдений } & \multicolumn{2}{|c|}{ Наработка до проведения технического обслуживания, тыс. км } \\
\cline { 2 - 3 } & для инжектора & для топливного насоса \\
\hline I регион & 20,2 & 15,6 \\
\hline II регион & 18,4 & 14,2 \\
\hline III регион & 16,5 & 12,3 \\
\hline IV регион & 14,3 & 12,1 \\
\hline
\end{tabular}

онных наблюдений (рис. 4 и 5) и получены следующие оптимальные значения для проведения технического обслуживание, которые приведены в табл. 7.

\section{Выводы}

1. Разработана и обоснована методика проведения эксплуатационных наблюдений для определения и объективной оценки показателей безотказности элементов инжекционной системы питания двигателей при их эксплуатации в климатических условиях территории Узбекистана.

2. Установлено, что загрязненность топлива в баках автомобилей, работающих в зонах Республики Узбекистан, находится на уровне 105,3...276 г/т, а запыленность воздуха окружающей среды $0,16 \ldots 0,75$ г/м ${ }^{3}$.

3. Предложена схема для анализа характера, причин возникновения и последствий отказов элементов инжекционной системы питания двигателей, которая позволяет решить комплексные вопросы по повышению безотказности системы. Выявлено, что основными причинами, вызывающими отказ элементов инжекционной системы питания двигателей, являются эксплуатационные факторы, а именно высокая запыленность окружающей среды и загрязненность топлива в баках автомобилей, а также выделение смолистых отложений из используемых некачественных бензинов.

4. Определены численные значения показателей надежности элементов инжекционной системы питания двигателей для климатических условий эксплуатации автомобилей в Центральной Азии, т.е. интенсивность общих отказов по системе питания составляет 0,03, 0,031, $0,036,0,036$ отказов/1000 км для регионов 1-4 соответственно.

5. С использованием разработанного сплайн-метода моделирования обработки результатов экспериментальных плотностей распределения отказов исследований определена оптимальная периодичность выполнения технического обслуживания инжекционной системы питания двигателей, которая составляет 20,2; 18,4; 16,3; 14,5 тыс. км соответственно для регионов 1-4.

\section{Список литературы}

[1] Лялькин Г.Б., Бердышев О.В. Математическая обработка результатов эксперимента. Пермь: Изд-во ПНИПУ, 2013, 186 с. [Lial'kin G.B., Berdyshev O.V. Mathematical processing of results of experiment. Perm National Research Polytechnic University, 2013, 186 p. (in Russian)]

$$
-103-
$$


[2] Основы научныхх исследований: Ред. А.А. Лудченко, 2-е изд., стер. К.: О-во «Знание», KOO, 2001, 113 c. [Fundamentals of scientific research. Ed. By A.A.Ludchenko, Znanie, 2001, 113 p. (in Russian)]

[3] Румшинский Л.3. Математическая обработка результатов эксперимента. М.: Наука, 1971, 322 c. [Rumshinskii L.Z. Mathematical processing of results of experiment, Moscow, Nauka, 1971, 322 p. (in Russian)]

[4] Шенк Х. Теория инженерного экспримента. М.: Наука, 1972, 384 с. [Shenk Kh. Theory of engineering experiment, Moscow, Nauka, 1972, 384 p. (in Russian)]

[5] Касымов С.С., Зайниддинов Х.Н. ДАН РУз, 2002, 3, 9-12 [Kasymov S.S., Zayniddinov Kh.N. Republic Uzbekistan Reports of the Sciences Academy, 2002, 3, 9-12]

[6] Каюмов Б.А., Зайниддинов Х.Н., Алматаев Т.О. А. с. DGU 00641 (2003). Б. И., 2003, 2 [Kaiumov B.A., Zayniddinov Kh.N., Almataev T.O. Patent DGU 00641 (2003)] 